\title{
The Clinical Profile of Death Among Aged Iranian Schizophrenic Patients: A Local Pilot Evaluation
}

ISSN: 2578-0093

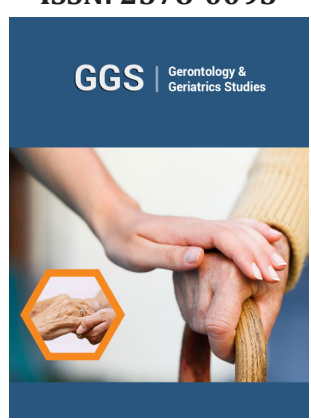

*Corresponding author: Saeed Shoja Shafti, Professor of Psychiatry, University of Social Welfare and Rehabilitation Sciences, Razi Psychiatric Hospital, Tehran, Iran

Submission: March 18, 2020

Published: 監 May 05, 2020

Volume 5 - Issue 5

How to cite this article: Saeed Shoja Shafti*, Alireza Memarie, Masomeh Rezaie Behjat Rahimi. The Clinical Profile of Death Among Aged Iranian Schizophrenic Patients: A Local Pilot Evaluation. Geronto \& Geriatric stud. 5(5). GGS.000625. 2020. DOI: $10.31031 /$ GGS.2020.05.000625

Copyright@ Saeed Shoja Shafti, This article is distributed under the terms of the Creative Commons Attribution 4.0 International License, which permits unrestricted use and redistribution provided that the original author and source are credited.

\section{Saeed Shoja Shafti*, Alireza Memarie, Masomeh Rezaie and Behjat Rahimi}

Professor of Psychiatry, University of Social Welfare and Rehabilitation Sciences, Razi Psychiatric Hospital, Tehran, Iran

\begin{abstract}
Introduction: Comorbidity between mental disorders and physical illnesses is the rule rather than the exception. Approaches to study the impact of comorbidity become challenging also due to lack of consensus about how to define and measure the concept of comorbidity. The aim of the present study was to evaluate the clinical profile of medical comorbidity among a group of local chronic elderly schizophrenic patients to see their prevalence and physiognomies.
\end{abstract}

Methods: while the geriatric section of Razi psychiatric hospital had been selected as the field of investigation, all elderly schizophrenic patients, who have been hospitalized there for lifelong, had been selected as accessible sample and surveyed with respect to recorded checkups and comorbid medical diagnoses. Psychiatric diagnosis was in essence based on 'Diagnostic and Statistical Manual of Mental Disorders', 5th edition (DSM-5) and medical diagnosis was principally based on 'International Classification of Diseases', 10th edition.

Results: Assessment had been performed on 168 aged schizophrenic patients ( $\geq 65$ years old) including 101 men and 67 women. According to the results, 89\% (n=151) of the elderly patients had some kind of registered non-psychiatric co-morbidity, which was meaningful higher than the frequency of comorbidity among a senior group of local residents. Amongst recorded co-morbidities: falls, hypertension and osteoarthritis were the most prevalent comorbidities with a frequency around $48.8 \%, 44.6 \%$ and $39.2 \%$, respectively. Hypertension, renal disease and malnutrition were significantly more prevalent among male patients $(\mathrm{p}<0.0000, \mathrm{p}<0.0045$ and $\mathrm{p}<0.0018$, in turn) and hyponatremia, aspiration/ asphyxiation and seizure were meaningfully more prevalent among female patients $(p<0.0075, p<0.0000$ and $\mathrm{p}<0.0009$, one-to-one). As stated by the findings and in comparison, with the senior group of local people, while diabetes, renal diseases and malnutrition were significantly more frequent, coronary artery disease, gastrointestinal disorder and osteoarthritis were significantly less frequent among the present sample of elderly schizophrenic patients.

Conclusion: While in comparison with a senior group of local people, the rate of medical comorbidities, particularly diabetes, renal diseases and malnutrition, were significantly higher in chronic elderly schizophrenic patients, a significant difference; as well, was the interrelated items between male and female patients, which demands further methodical and gender-based studies to define proper care and interventions for this vulnerable group of patients.

Keywords: Schizophrenia; Psychiatric disorders; Medical comorbidity; Elderly mental patients; Senior group of people; Chronic patients.

\section{Introduction}

Researchers have consistently reported that people with mental disorders have elevated mortality compared with the general population [1,2]. Since then, numerous studies and reviews have been conducted on the mortality risks of people with a variety of mental disorders [3,4]. The link between mental disorders and mortality is complicated because most people with mental disorders do not die of their condition; rather, they die due to heart disease, infection, suicide, and etc. [5,6]. On the other hand, mental disorders are associated with risk factors for mortality [7]. In this regard, people with mental disorders have high rates of adverse health behaviors, including tobacco smoking, substance abuse, physical inactivity, and poor diet $[7,8]$. Although schizophrenia is not in itself a lethal illness, over-mortality among such group of psychiatric patients, in comparison to the reference population, has been attested to for a long time [9].

Until the use of antibiotics, this over-mortality was mainly due to infectious diseases caused by the close quarters in mental institutions. At the present time, this over-mortality is 
mainly due to suicide but also with a noteworthy mortality by certain natural causes such as respiratory diseases and cardiovascular or cerebrovascular accidents [9]. On the other hand, the health needs of older adults have grown enormously as the population ages, and geriatric physicians and psychiatrists play major roles in treating this group of people [10]. While the leading causes of death among older persons are heart disease, cancer, and stroke [11], the National Institute of Mental Health's Epidemiologic Catchment Area (ECA) program has found that the most common mental disorders of old age are depressive disorders, cognitive disorders, phobias, and alcohol use disorders [12]. Meanwhile, elderly persons have a higher risk for suicide than any other population [13].

In this regard, some scholars believe that mortality is meaningfully higher among persons with mental disorders than among the comparison population [1], and mortality risk of chronic psychiatric patients is notably higher than general population, despite ongoing improvements in medical care and facilities [1416]. But there are other scholars, too, who believe that standardized mortality ratios are lowest in geriatric psychiatric patients [17] and the ostensible over-mortality tends to disappear in elderly subjects [18]. Also with regard to leading causes of death, while some of researchers believe that long-stay psychiatric patients were found to die from the same natural causes as the rest of the general population [11,16], others accentuate on more specific causes $[19,20]$. Since there is not any systematic psychiatric case register in Iran, which could allow us to study accurately the mortality of psychiatric patients, the aim of the current study was to determine the rate and clinical profile of death in a group of non-western chronic elderly schizophrenic patients.

\section{Methods}

Razi psychiatric hospital in south of capital city of Tehran, as one of the largest and oldest public psychiatric hospitals in the Middle East, which has been established formally in 1917 and with a capacity around 1375 active beds, had been selected as the field of study in the present retrospective assessment. Moreover, amongst its separate existent sections, chronic geriatric ward of the hospital with a capacity around 220 beds ( 110 for each of male and female elderly patients) had been selected as the specific arena of investigation. So, for survey, all recorded deceases during the last sixty months (April of 2014-August 2019) in the above-mentioned zones had been incorporated in the current study. While clinical diagnosis was based on 'Diagnostic and Statistical Manual of Mental Disorders', $5^{\text {th }}$ edition (DSM-5) [21], all hospitalized patients in the said wards, as accessible sample, were schizophrenic patients.

\section{Statistical analysis}

'T-test' and 'comparison of proportions' had been used as statistic formularies for assessment of data. Statistical significance, as well, had been defined as $\mathrm{p}$ value $\leq 0.05$. MedCalc Statistical Software version 15.2 was used as statistical software tool for analysis.

\section{Results}

Among eight-hundreds and frothy elderly schizophrenic patients hospitalized in the chronic geriatric section of Razi psychiatric hospital ( $n=505 \& n=335$, for male and female aged patients, respectively), during the last sixty-four months, sixtynine deceases (thirty-nine deaths among males, and thirty expiries among females) had been registered by the mortality committee of the hospital. As said by results, the annual rate of mortality among elderly psychiatric patients in the present assessment was around 0.015 (0.15 per 1,000 individuals per year) and 0.017 (0.17 per 1,000 individuals per year) among male and female patients, respectively, which could not show any significant difference between them, incidentally $(\mathrm{z}=-0.6370, \mathrm{p}-<0.52$, CI $95 \%=-0.05$, 0.02).

Table 1: Proportional grade of causes of decease in aged schizophrenic patients.

\begin{tabular}{|c|c|c|c|c|c|}
\hline Rank & Cause of Death & Male & Female & Total & $\%$ \\
\hline 1 & Myocardial infarction & 4 & 5 & 9 & 13.04 \\
\hline 2 & $\begin{array}{l}\text { Aspiration and } \\
\text { asphyxiation }\end{array}$ & 4 & 4 & 8 & 11.59 \\
\hline 2 & Electrolyte imbalance & 5 & 3 & 8 & 11.59 \\
\hline 3 & Cancer & 4 & 3 & 7 & 10.14 \\
\hline 3 & Sudden Cardiac death & 3 & 4 & 7 & 10.14 \\
\hline 4 & Respiratory failure (COPD) & 4 & 2 & 6 & 8.69 \\
\hline 4 & Septicemia & 2 & 4 & 6 & 8.69 \\
\hline 5 & Cerebrovascular accident & 4 & 1 & 5 & 7.24 \\
\hline 5 & Congestive heart failure & 3 & 2 & 5 & 7.24 \\
\hline 6 & Pneumonia & 3 & 1 & 4 & 5.79 \\
\hline 7 & Renal failure & 2 & 0 & 2 & 2.89 \\
\hline 8 & $\begin{array}{c}\text { Pulmonary } \\
\text { thromboembolism }\end{array}$ & 1 & 0 & 1 & 1.44 \\
\hline 8 & Encephalitis & 0 & 1 & 1 & 1.44 \\
\hline
\end{tabular}

Nevertheless, they were significantly lower than the presentday local crude death rate (4.84 deaths $/ 1000$ population) $(\mathrm{z}=6.09$, $\mathrm{p}<0.000$, CI $95 \%=0.005,0.002)$. On the other hand, the mean standard deviation (SD) of the age of the deceased patients were around $68.2 \pm 6.81$ and $73.57 \pm 6.82$ for male and female patients, respectively, which showed a significant difference, by the way $(\mathrm{t}=3.245$, probability $<0.001$, CI $95 \%=2.07,8.67)$. Furthermore, in comparison with the life expectancy in Iran, based on the latest WHO data published in 2018, which was around 74.6 and 76.9 for males and females, respectively (total=75.7), findings of the present assessment had displayed a substantial shortening of life among male and female patients $(\mathrm{t}=21.11, \mathrm{p}<0.000$, CI 95\%=5.81, 6.99, and $\mathrm{t}=8.93, \mathrm{p}<0.000, \mathrm{CI} 95 \%=2.60,4.06$, respectively). With regard to leading causes of death, results of the present estimation had exposed that cardiac disorders, in total, was the main leading cause of death among aged schizophrenic patients (Table 1). Regarding other causes of death, like stroke, lower respiratory infections, chronic obstructive pulmonary disease, and malignancy, the present ranking was rather roughly in accord with the national or universal data, maybe due to presence of preventable problems like electrolyte imbalance or aspiration \asphyxiation, which demands more medical cautiousness or monitoring. Moreover, with regard to malignancy, trachea, bronchus or lung cancers was evident in only two male patients, and the rest included stomach, pancreas 
and brain cancers, as well as lymphoma. Likewise, other causes like violence, suicide, road traffic accidents, falls, fires, drug abuse, tuberculosis, drowning, epilepsy, and Parkinson's disease, were not applicable here.

\section{Discussion}

While mental disorders are supposed to be associated with an elevated risk of premature mortality [1], inadequately organized somatic care and the prevailing culture of "non-somatic" treatment in psychiatry were suggested to explain this phenomenon, at least to some extent [16]. Likewise, such a problem could be exacerbated by the shift in psychiatric care from inpatient facilities to community settings, jails, and prisons [22]. There is evidence that this mortality risk is especially high soon after discharge from inpatient psychiatric services [23,24]. Elderly patients have more concomitant, chronic, and multiple medical problems and take more medications than younger adults [25]. On the other hand, many of these medications can influence their mental status [26]. Back to our discussion and with respect to the mortality rate, our conclusion was somewhat in accord with the outcomes of Ran et al. [17], who supposed that standardized mortality ratios were highest in young subjects and lowest in geriatric subjects [17]. But, it was not in agreement with the inferences of Lim et al. [14], Hewer et al. [15], and Räsänen et al. [16], who presumed that the mortality risk of the long-stay psychiatric patients compared with that of the general population was notably higher.

Furthermore, it was in partial agreement with Bralet et al. [18], who said that though the average mortality in schizophrenia is twice higher than among the general population, this over-mortality is highest among the 20-40 years range of age and added risk tends to disappear after 60 years [18]. So, the reports of Walker et al. [1] that mortality is significantly higher among people with mental disorders than among the comparison population and mental disorders rank among the most substantial causes of death worldwide may demand reconsideration. Also, while in the present assessment and with respect to mortality rate there was not any meaningful difference between old male and female psychiatric patients, this finding was not in harmony with the deduction of Tabbane et al. [19], who stated that the supposed over-mortality concerned only schizophrenic male patients, whereas schizophrenic females did not have an over-mortality [19]. In addition, while a substantial difference was evident between male and female old patients as regards the age of death, which was significantly longer on behalf of female patients, the latter finding is coherent with the fact that on average, women live longer than men [11], and may highlight some kind of biological vulnerability, which demands further genderrelated clinical investigations. Moreover, with respect to genderbased mortality rate, our verdict was not compatible with the assumptions of Gausset et al. [27], who supposed that among severe mental patients, mortality rates are higher for men than women. Similarly, as regards life expectancy, outcomes of the current evaluation, which showed a significant shortening of life among elderly male and female schizophrenic patients, were consistent with the findings of Zgueb et al. [28], who stated that psychiatric inpatients seem to be at high risk of premature death and Zubenko et al. [29] , who supposed that the mental disorders of late life have a significant negative impact on the survival of older psychiatric patients. With regard to leading causes of death, outcomes of the present assessment had exposed that cardiac disorders, in total, was the main leading cause of death among geriatric patients, which was in agreement with the conclusions of Trollor et al. [11] and Räsänen et al. [16], who believed that long-stay psychiatric patients usually die from the same natural causes as the rest of the general population. Regarding other causes of death, the present ranking was rather roughly in accord with the findings of Lim et al. [14], Hewer et al. [15], Tabbane et al. [19], and Abiodun OA [20].

Such a difference maybe is a bit due to preventable problems like electrolyte imbalance or aspiration \asphyxiation, which had occupied the second place, among all causes of death, and demands more medical cautiousness or monitoring. Also, with respect to infection and pneumonia, our results were not consistent with the assumptions of Lim et al. [14], and Abiodun OA [20], who had declared, in general, infection and pneumonia as the most important causes of death. The later finding, perhaps, could be attributed to proper scrubbing and ventilation, which may well reduce the risk of infections. But, regarding sudden cardiac death our conclusion was somewhat compatible with the finding of Abiodun OA, who had found sudden unexplained deaths in a noticeable number of cases [20]. Also, in opposite to Walker et al. [1] and Bralet et al. [18], in our study unnatural causes, like suicide, did not have any place among main causes of death. Nonetheless, as regards the role of malignancy, it was rather in harmony with the statement of Tabbane et al.[19], who thought that cancer mortality in schizophrenic patients is still debated [19].

In general, at all times a pretreatment medical evaluation, plus periodic checkups, based on standard protocols, is essential [30]. For example, any changes in blood pressure and pulse rate or emergence of drug induced side effects should be watched [31]. Also, suitable attention should be focused on clinical examinations and various health educational programs that address issues like healthy diet, smoking cessation and physical exercise [32]. The importance of mortality studies remains twofold: they are a good indicator of the quality of health care policy, and also they enable the formulation of research hypotheses if you point out specific causes of death in a sub-group like schizophrenics, in comparison with the general population [33]. For patients hospitalized with psychiatric disorders, the time shortly after discharge is the period in which they are at the highest risk for premature death from a variety of causes [22]. So, clinicians should keep these patients safe by serving as a liaison between primary and secondary health care services to ensure patients are receiving holistic care, which meets their physical and mental health needs as well as addresses their psychosocial problems [22]. Identifying risk factors for deaths in psychiatric hospitals highlights necessary changes in psychiatric management strategies by taking into account the patient's characteristics in addition to drugs' safety profile. Further methodical studies are required for distinguishing the risk factors of premature death in psychiatric inpatients. Recognizing such kind of risk factors is necessary for development of efficient preventive strategies [28]. 


\section{Conclusion}

While the age of the deceased female patients was significantly longer than the expired male patients, life expectancy of both male and female patients was meaningfully shorter than local public life expectancy. Certainly, based on the exposed reliabilities or discrepancies, in comparison with the outcomes of related studies, for development of efficient preventive strategies, further methodical and prospective studies are required for clarification of risk factors of premature death in psychiatric inpatients.

\section{References}

1. Walker ER, McGee RE, Druss BG (2015) Mortality in mental disorders and global disease burden implications: A systematic review and metaanalysis JAMA Psychiatry 72(4): 334-341.

2. Harris EC, Barraclough B (1998) Excess mortality of mental disorder. Br J Psychiatry 173: 11-53.

3. Lawrence D, Kisely S, Pais J (2010) The epidemiology of excess mortality in people with mental illness. Can J Psychiatry 55(12): 752-760.

4. Chesney E, Goodwin GM, Fazel S (2014) Risks of all-cause and suicide mortality in mental disorders: a meta-review. World Psychiatry 13(2): 153-160.

5. Saha S, Chant D, McGrath J (2007) A systematic review of mortality in schizophrenia: is the differential mortality gap worsening over time? Arch Gen Psychiatry 64 (10): 1123-1131.

6. Cuijpers P, Vogelzangs N, Twisk J, Kleiboer A, Li J, et al. (2014) Comprehensive meta-analysis of excess mortality in depression in the general community versus patients with specific illnesses. Am J Psychiatry 171(4): 453-462.

7. Colton CW, Manderscheid RW (2006) Congruencies in increased mortality rates, years of potential life lost, and causes of death among public mental health clients in eight states. Prev Chronic Dis 3(2): 42.

8. Whiteford HA, Degenhardt L, Rehm J, Baxter AJ, Holly EE, et al. (2013) Global burden of disease attributable to mental and substance use disorders: findings from the Global Burden of Disease Study 2010. Lancet 382(9904): 1575-1586.

9. Laursen TM, Nordentoft M, Mortensen PB (2014) Excess early mortality in schizophrenia. Annu Rev Clin Psychol 10: 425-448.

10. Balzer DG, Steffens DC, Busse EW (2012) Essentials of geriatric psychiatry. In: $\left(2^{\text {nd }}\right.$ edn $)$, American Psychiatric Association, Arlington, USA.

11. Trollor JN, Anderson TM, Sachdev PS, Brodaty H, Andrews G (2007) Prevalence of mental disorders in the elderly: The Australian national mental health and well-being survey. Am J Geriatr Psychiatry 15(6): 455-466.

12. Bartels SJ, Naslund JA (2013) The underside of the silver tsunami-older adults and mental health care. N Engl J Med 368(6): 493-496.

13. Kessler RC, Berglund P, Demler O, Jin R, Merikangas KR, et al. (2005) Lifetime prevalence and age-of-onset distributions of DSM-IV disorders in the National Comorbidity Survey Replication. Arch Gen Psychiatry 62(6): 593-602.

14. Lim LC, Sim LP, Chiam PC (1991) Mortality among psychiatric inpatients in Singapore. Singapore Med J 32 (3): 130-132.

15. Hewer W, Rössler W (1997) Mortality of patients with functional psychiatric illnesses during inpatient treatment. Fortschr Neurol Psychiatr 65(4): 171-181.
16. Räsänen S, Hakko H, Viilo K, Rochow VB, Moring J (2003) Excess mortality among long-stay psychiatric patients in Northern Finland. Soc Psychiatry Psychiatr Epidemiol 38(6): 297-304.

17. Ran MS, Chan CL, Chen EY, Tang CP, Lin FR, et al. (2008) Mortality of geriatric and younger patients with schizophrenia in the community. Suicide Life Threat Behav 38(2): 143-151.

18. Bralet MC, Yon V, Loas G, Noisette C (2000) Cause of mortality in schizophrenic patients: prospective study of years of a cohort of 150 chronic schizophrenic patients. Encephale 26(6): 32-41.

19. Tabbane K, Joober R, Spadone C, Poirier MF, Olié JP (1993) Mortality and cause of death in schizophrenia. Review of the literature. Encephale 19(1): 23-28.

20. Abiodun OA (1988) Mortality in a psychiatric population: a Nigerian psychiatric hospital experience. Acta Psychiatr Scand 77(6): 654-657.

21. American Psychiatric Association (APA) (2013) Diagnostic and statistical manual of mental disorders. In: $\left(5^{\text {th }}\right.$ edn), DC: American Psychiatric Association, Washington, USA.

22. Lamb HR, Weinberger LE (2005) The shift of psychiatric inpatient care from hospitals to jails and prisons. J Am Acad Psychiatry Law 33(4): 529-534.

23. Crump C, Ioannidis JP, Sundquist K, Winkleby MA, Sundquist J (2013) Mortality in persons with mental disorders is substantially overestimated using inpatient psychiatric diagnoses. J Psychiatr Res 47(10): 1298-1303.

24. Meloni D, Miccinesi G, Bencini A, Conte M, Crocetti E, et al. (2006) Mortality among discharged psychiatric patients in Florence, Italy. Psychiatr Serv 57 (10): 1474-1481.

25. Thakur ME, Blazer DG, Steffens DC (2014) Clinical manual of geriatric psychiatry. American Psychiatric Publishing, Arlington, USA.

26. Reifler BY, Colenda CC, Juul D (2012) Geriatric psychiatry. In: Aminoff MJ, Faulkner LR (Eds.), The American Board of Psychiatry and Neurology: Looking Back and Moving Ahead. American Psychiatric Publishing, Arlington, USA, p. 135.

27. Gausset MF, Casadebaig F, Bataille JM, Quemada N, Terra JL (1992) Mortality of mentally ill patients. Review of the literature. Encephale 18 (1): 93-100.

28.Zgueb Y, Jomli R, Ouertani A, Hechmi S, Ouanes S, et al. (2014) Deaths in a Tunisian psychiatric hospital: an eleven-year retrospective study]. Encephale 40(5): 416-422.

29.Zubenko GS, Mulsant BH, Sweet RA, Pasternak RE, Tu XM (1997) Mortality of elderly patients with psychiatric disorders. Am J Psychiatry 154(10): 1360-1368.

30. Byers AL, Yaffe K, Covinsky KE, Friedman MB, Bruce ML (2010) High occurrence of mood and anxiety disorders among older adults: The National Comorbidity Survey Replication. Arch Gen Psychiatry 67(5): 489-496.

31. Balzer DG, Steffens DC (2012) Essentials of Geriatric Psychiatry. In: $\left(2^{\text {nd }}\right.$ edn), American Psychiatric Association, Arlington, USA.

32. Meesters P, Haan L, Comijs HC, Stek ML, Janssen MMS, et al. (2012) Schizophrenia spectrum disorders in later life: Prevalence and distribution of age at onset and sex in a Dutch catchment area. Am J Geriatr Psychiatry 20(1): 18-28.

33. Casadebaig F, Philippe A (1999) Mortality in schizophrenic patients. 3 years follow-up of a cohort. Encephale 25(4): 329-337. 